Бейсекеева Диляра Болатқызы, Магистрант E-mail: dilyarabolatovna@ gmail.com ORCID ID: 0000-0001-5760-0312 Боранбаев Сейлхан Нарубтинович, доктор технических наук, профессор E-mail: sboranba@yandex.kz ORCID ID: 0000-0002-7289-2648 Евразийский Национальный университет им. Л.Н.Гумилева г. Астана, Республика Казахстан

\title{
РАЗРАБОТКА МОБИЛЬНОГО ПРИЛОЖЕНИЯ ДЛЯ ЗАНЯТИЯ ФИТНЕСОМ
}

Beisekeyeva Dilyara, Master student E-mail: dilyarabolatovna@ gmail.com ORCID ID: 0000-0001-5760-0312

Boranbayev Seilhan, Doctor of Technical Sciences, professor E-mail: sboranba@yandex.kz ORCID ID: 0000-0002-7289-2648

L.N.Gumilyov Eurasian National University Astana, the Republic of Kazakhstan

\section{THE DEVELOPMENT OF A MOBILE APPLICATION FOR FITNESS}

Annotation: The article is devoted to the development of a mobile fitness app. The application contains many functions for people of different ages, facilitates the search for an appropriate gym, including those or other suitable for them individual areas of fitness programs. The main functions of the application: search for existing fitness programs, according to user data entered during registration; record for training in the chosen direction of the fitness program; feedback (complaints and wishes of the user); nutrition diary for daily monitoring of diets and proper nutrition during trainings prescribed by the trainer; training page with videos for training and motivating users.

Keywords: sports, mobile applications, Android, Android Studio, JavaScript, MySQL

Аннотация: Статья посвящена разработки мобильного приложения для занятия фитнесом. Приложение содержит множество функиий для людей разных возрастов, облегчает поиск соответствующего спортивного зала, включающего те или иные подходящие для них индивидуальные направления фитнес-программ. Основные функции приложения: поиск существующих фитнес-программ, согласно данных пользователя, введенных при регистрации; запись на тренировку по выбранному направлению фитнес-программы; обратная связь (жалобы и пожелания пользователя); дневник питания для ежедневного мониторинга диет и правильного питания во время тренировок, прописанных тренером; обучающая страница с видеороликами для обучения и мотивации пользователей.

Ключевые слова: спорт, мобильные приложения, Android, Android Studio, JavaScript, MySQL

\section{1. Введение}

Сфера спортивной деятельности с каждым днем обретает большую популярность. Мобильные приложения для занятия спортом, отслеживания спортивных новостей становятся все больше востребованными и их разработка является актуальной, поскольку они имеют миллионную аудиторию пользователей. Разработанное мобильное приложение для занятия фитнесом позволяет пользователям различных возрастов сделать поиск необходимого спортивного зала, включающего те или иные подходящие для них индивидуальные направления фитнес-программ, записаться на тренировку по выбранному направлению фитнес-программы, контролировать индивидуальную программу правильного питания и др. 
Для разработки мобильного приложения «Your Choice» была выбрана среда разработки - Android Studio, в качестве эмулятора был выбран официальный эмулятор Android SDK. Язык программирования для написания основного функционала (регистрация, авторизация, заполнение анкеты, поиск направлений согласно данным анкеты и т.д) - JavaScript. B качестве сервера базы данных был использован MySQL. Передача данных осуществляется по формату JSON. Разработан функционал авторизации пользователя и регистрации для дальнейшего использования приложения, как помощника в поиске подходящей спортивной программы.

\section{2. Мобильное приложение для занятия фитнесом}

Основные действия пользователя при использовании мобильного приложения:

1. При запуске приложения пользователь видит окно, где отображаются кнопки «Регистрация» и «Войти» (Рисунок 1).

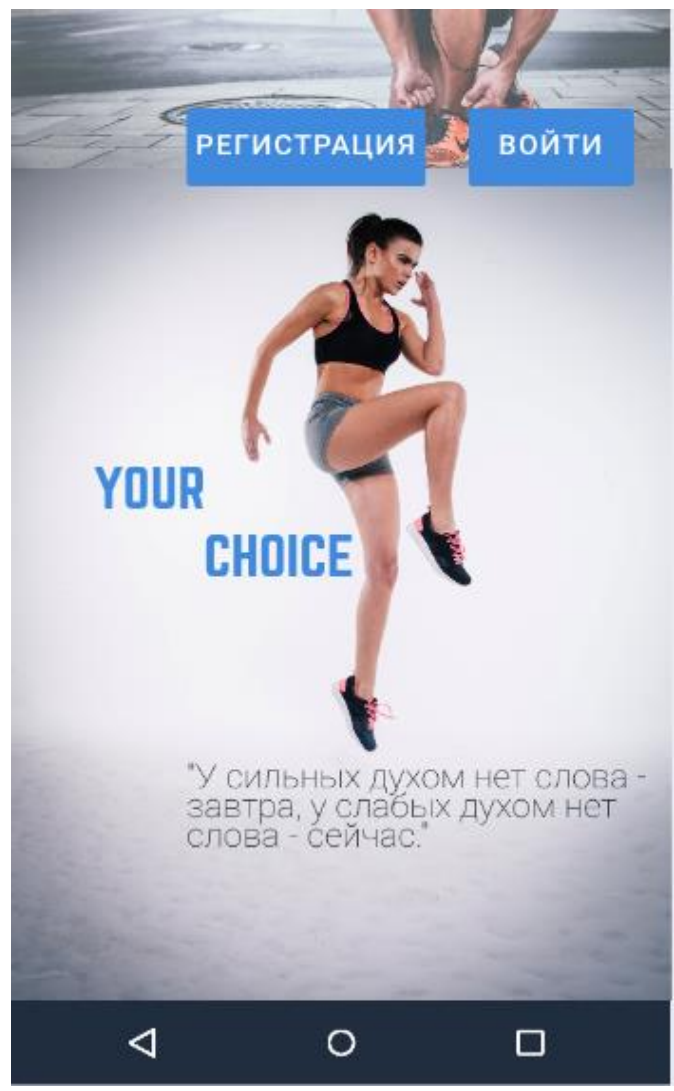

Рисунок 1. Стартовое окно мобильного приложения

2. Регистрация, если данный пользователь отсутствует в базе, в противном случае авторизация. Для регистрации пользователя используется номер телефона пользователя в дальнейшем будет использоваться как логин, а пароль - сочетание цифр и букв (рис. 2, рис.3). 


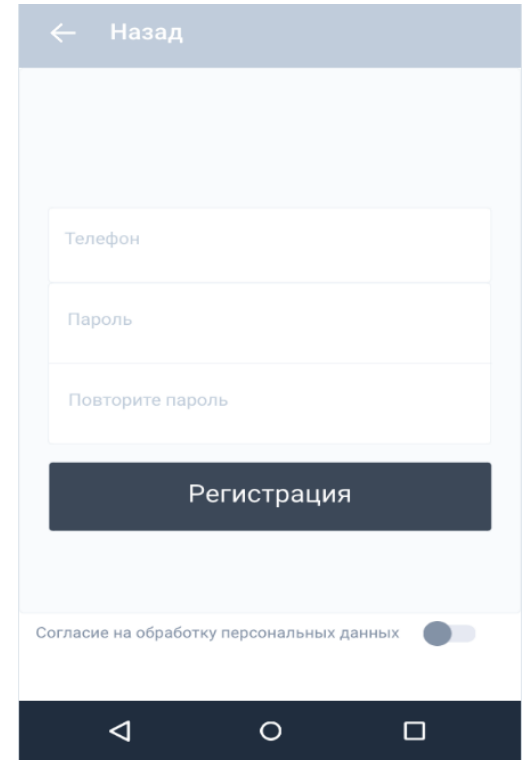

Рисунок 2. Окно регистрации

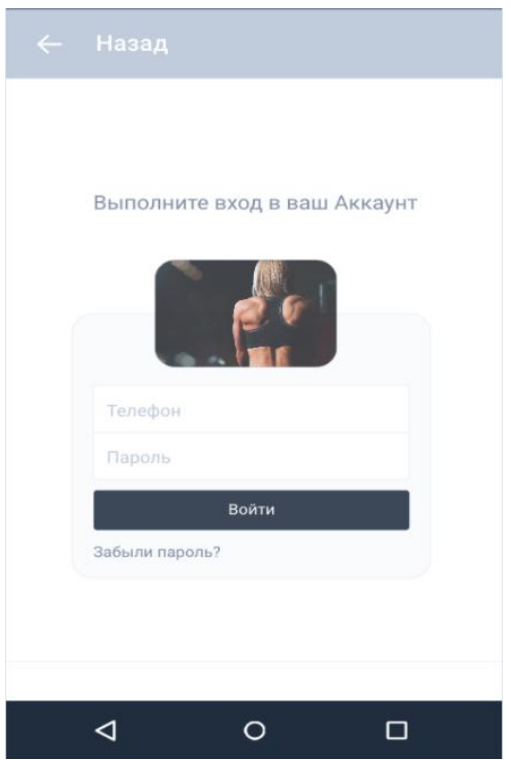

Рисунок 3. Окно авторизаџии

3. При регистрации, после присваивания пользователю собственного аккаунта, пользователю необходимо заполнить обязательные поля (в виде анкеты) - «ФИО», «Возраст» - от 6 до 80 лет, «Пол» - мужской или женский, «Статус» - новичок, любитель, профессионал, «Направление» на выбор: фитнес, йога, стрейчинг, пилатес, кроссфит, танцы, плавание, иное (другой вид спорта).

4. После заполнения анкеты, пользователь переходит в главное меню, где отображаются все подходящие для него программы, которые сортируются по фильтрам данных, указанных пользователем при заполнении анкеты (возраст, пол, статус, направление). Последовательность при регистрации показана на рисунке 4.

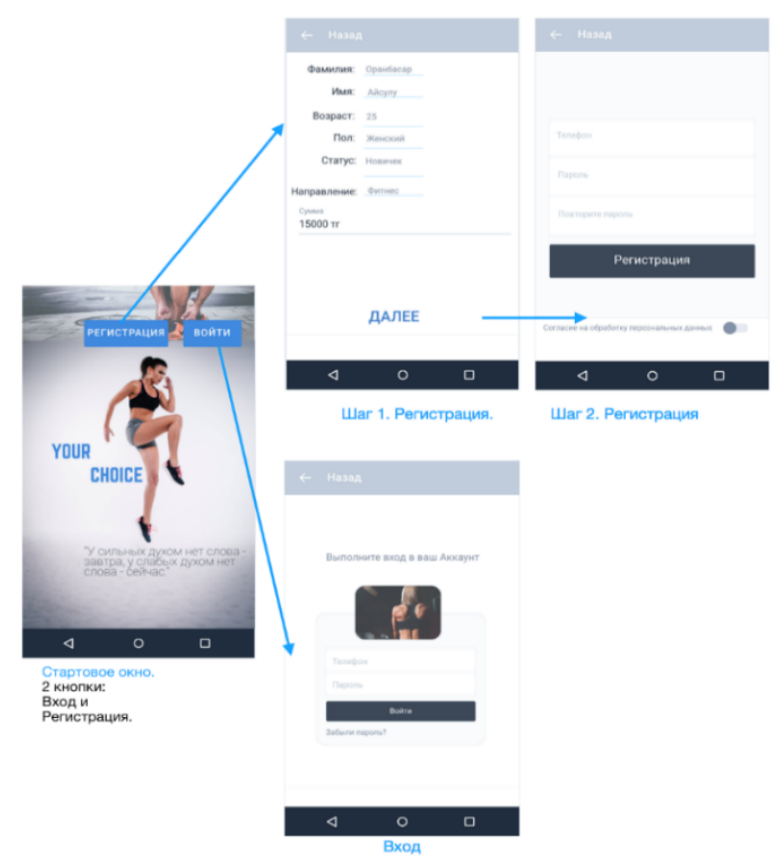

Рисунок 4. Последовательность действий при регистрации пользователя 
5. При выборе подходящего направления, у пользователя есть возможность подать заявку, которую обрабатывает администратор фитнес-клуба данного направления (в заявке отображаются контакты пользователя и текст сообщения). Заявки обрабатываются администратором.

6. В личном кабинете у пользователя имеется обучающая страница и дневник питания. Обучающая страница содержит различные видеоролики профессионалов по разным направлениям. Дневник питания содержит записи о калориях, сожженых во время тренировки, для анализа результата тренировок.

\section{3. Заключение}

Поиск спортивных направлений основан на данных заполненной пользователем анкеты. Администратор клуба имеет личный кабинет, где в меню приложения имеется следующий функционал:

1. Меню «Программы» - существующие программы клуба.

2. Меню «Добавить программу» - функционал добавления программы, где администратор имеет возможность заполнять форму в виде анкеты с полями «Наименование» - наименование программы, «Пол»- мужской, женский на выбор, есть возможность выбора сразу двух критериев, «Статус» - новичок, любитель, профессионал, «Возраст» - от 6 до 80 лет, «Направление» - тип программы на выбор: фитнес, йога, стрейчинг, пилатес, кроссфит, танцы, плавание, иное (другой вид спорта).

3. Меню «Заявки» - сообщения пользователей о записи на выбранную программу с указанными контактами для дальнейшей связи с ними.

4. Меню «Жалобы и пожелания» - жалобы и пожелания пользователей для дальнейших рациональных предложений по улучшению работы тренеров, для создания различных интересующих программ, а также для улчушения работы спортивного клуба в целом. 